\title{
Acute effects of deep diaphragmatic breathing in COPD patients with chronic respiratory insufficiency
}

\author{
M. Vitacca, E. Clini, L. Bianchi, N. Ambrosino
}

Acute effects of deep diaphragmatic breathing in COPD patients with chronic respiratory insufficiency. M. Vitacca, E. Clini, L. Bianchi, N. Ambrosino. OERS Journals Ltd 1998.

ABSTRACT: This study investigated the impact of deep diaphragmatic breathing (DB) on blood gases, breathing pattern, pulmonary mechanics and dyspnoea in severe hypercapnic chronic obstructive pulmonary disease (COPD) patients recovering from an acute exacerbation.

Transcutaneous partial pressure of carbon dioxide $\left(P \mathrm{tc}, \mathrm{CO}_{2}\right)$ and oxygen $\left(P \mathrm{tc}, \mathrm{O}_{2}\right)$ and arterial oxygen saturation $\left(\mathrm{S}_{\mathrm{a}}, \mathrm{O}_{2}\right)$, were continuously monitored in $25 \mathrm{COPD}$ patients with chronic hypercapnia, during natural breathing and DB. In eight of these patients, breathing pattern and minute ventilation $\left(V^{\prime} E\right)$ were also assessed by means of a respiratory inductance plethysmography. In five tracheostomized patients, breathing pattern and mechanics were assessed by means of a pneumotachograph/pressure transducer connected to an oesophageal balloon. Subjective rating of dyspnoea was performed by means of a visual analogue scale.

In comparison to natural breathing deep DB was associated with a significant increase in $P \mathrm{tc}, \mathrm{O}_{2}$ and a significant decrease in $\mathrm{Ptc}_{\mathrm{tc}} \mathrm{CO}_{2}$, with a significant increase in tidal volume and a significant reduction in respiratory rate resulting in increased $V^{\prime} E$. During DB, dyspnoea worsened significantly and inspiratory muscle effort increased, as demonstrated by an increase in oesophageal pressure swings, pressure-time product and work of breathing.

We conclude that in severe chronic obstructive pulmonary disease patients with chronic hypercapnia, deep diaphragmatic breathing is associated with improvement of blood gases at the expense of a greater inspiratory muscle loading.

Eur Respir J 1998; 11: 408-415.
Fondazione Salvatore Maugeri IRCCS, Lung function unit and Respiratory Department, Centro Medico di Gussago, Italy.

Correspondence: M. Vitacca

Fondazione Salvatore Maugeri IRCCS

Pulmonary Department

Centro Medico di Riabilitazione di

Gussago

Via Pinidolo 23

25064 Gussago (BS)

Italy

Fax: 39302521718

Keywords: Breathing pattern

chest physiotherapy

respiratory muscles

respiratory rehabilitation

Received: September 291997

Accepted after revision December 151997
Respiratory rehabilitation programmes, including endurance exercise training and breathing exercises have been shown to be effective in patients with chronic obstructive pulmonary disease (COPD) [1]. Nevertheless physiological studies on the effects of the single components of pulmonary rehabilitation are lacking [2]. Diaphragmatic breathing (DB) has been claimed, but not demonstrated, to correct abnormal chest wall motion, decrease the work of breathing (WOB) and dyspnoea and improve ventilation distribution [3]. Amвrosino et al. [4] reported improvement in maximal exercise tolerance in mild COPD pat-ients undergoing deep DB and pursed-lip breathing, but not in matched control patients. On the other hand, uncontrolled studies revealed a decrease in rib cage motion and an increase in abdominal motion during DB $[5,6]$, while pulmonary function and exercise capacity remain unchang-ed [7]. Recently, in a study during loaded and unloaded breathing in patients with moderate to severe COPD without respiratory insufficiency, with almost normal inspiratory muscle strength, DB detrimentally affected co-ordination of chest wall motion as well as mechanical efficiency, while dyspnoea sensation was not improved [8].

We wondered what might be the effects of that approach in more severe COPD patients, namely those with chronic respiratory insufficiency recovering from an episode of acute respiratory failure. In fact, the recent development of new therapeutic approaches, such as lung transplantation and lung volume reduction surgery, make severe COPD patients candidates for rehabilitation programmes. This is true even for those with chronic respiratory failure and hypercapnia. Therefore, this study was undertaken to investigate the impact of deep DB on blood gases, breathing pattern, and dyspnoea in severe hypercapnic COPD patients with reduced inspiratory muscle strength, recovering from a recent exacerbation of their disease. In a smaller group of patients we also examined the effects of DB on pulmonary mechanics.

\section{Materials and methods}

The study was approved by the Ethics Committee of Medical Centre of Gussago, S. Maugeri Foundation IRCCS, Italy. The study was conducted according to the declaration of Helsinki. Patients gave their informed consent to participate.

\section{Patients}

Twenty five patients were recruited during a period of 1 $\mathrm{yr}$ from those admitted to our Intermediate Intensive Care Unit, recovering from a recent episode of a noninfectious 
exacerbation of COPD. Diagnosis of COPD was made according to the American Thoracic Society (ATS) criteria [9]. In addition, at the time of the study arterial oxygen tension $\left(\mathrm{Pa}, \mathrm{O}_{2}\right)$ and arterial carbon dioxide tension $\left(\mathrm{Pa}_{\mathrm{a}}, \mathrm{CO}_{2}\right)$ had to be $<8.0 \mathrm{kPa}(60 \mathrm{mmHg})$ and $>6.0 \mathrm{kPa}(45 \mathrm{mmHg})$, respectively, during spontaneous breathing of room air. At the time the patients were recruited for this study, they were all in a stable condition, as assessed by stability of blood gas values, $\mathrm{pH}(>7.35)$ and haemodynamics. They did not need sympathicomimetics or suffer from a low cardiac output. All patients were free from their exacerbation for at least 7 days (range 8-14 days). Patients with other organ failure, cancer or inability to co-operate were excluded from the study. All patients were receiving longterm oxygen therapy, but none were on domiciliary longterm mechanical ventilation. During their exacerbation all patients had been treated with standard medical therapy including systemic steroids $(76 \%)$, inhaled bronchodilators $(100 \%)$ and oxygen. Fifteen patients had been treated with mechanical ventilation (six invasively and nine by mask) for 4-15 days; mechanical ventilation had been withdrawn for 8-12 days. One out of six invasively ventilated patients had been extubated, whereas five patients had undergone tracheostomy and were still tracheostomized but breathing spontaneously at the time of the study. Two of these patients had undergone short-term curarization (1 $\mathrm{mg} \cdot \mathrm{kg}^{-1}$ of succynilcholine) at the moment of intubation, but none of the patients underwent long-term curarization. Sedation was used in all patients undergoing invasive mechanical ventilation $(8-48 \mathrm{~h})$, but not in the nine patients ventilated noninvasively. When in a stable condition, before the exacerbation and at the time of the study, all patients were receiving treatment with inhaled bronchodilators, but no systemic or inhaled steroids $[9,10]$.

\section{Measurements and monitoring}

Dynamic and static lung volumes were measured by means of a volume-constant body plethysmograph (CADNET system 1085; Medical Graphic Corp, St. Paul, MN, USA). The predicted values of QUANJER [11] were used. Arterial blood gases were assessed by means of an analyser (ABL 300; Radiometer, Copenhagen, Denmark), using blood samples drawn from the radial artery while patients breathed room air in the sitting position. Inspiratory muscle strength was assessed by measuring maximal inspiratory pressure (MIP) at the level of functional residual capacity (FRC), according to the method of BLACK and HyatT [12], using a portable manometer (NIF; Markos, Monza. Italy: range: $0-150 \mathrm{cmH}_{2} \mathrm{O}$ ). Predicted values were those of Bruschi et al. [13]. Patients performed a minimum of three manoeuvres with at least a 1 min interval between efforts until two acceptable values not differing from each other by more than $5 \%$ were obtained. The best value was recorded.

In all patients, transcutaneous partial pressure of carbon dioxide $\left(P \mathrm{tc}, \mathrm{CO}_{2}\right)$ and oxygen $\left(P \mathrm{tc}, \mathrm{O}_{2}\right)$ were monitored continuously by means of an electrode system (TCM 3; Radiometer) after calibration with arterial blood gases [14]. An electrode was attached with plastic-mounting rings to the skin of the upper anterior part of the thorax, in the subclavian region. The electrode was heated to a temperature of $44^{\circ} \mathrm{C}$. Correlations (r) between arterial and transcutaneous values were 0.70 and 0.52 for carbon dioxide and oxygen, respectively. A 15-30 min interval was allowed for electrode stabilization according to the skin characteristics of the patient. Arterial oxygen saturation $\left(\mathrm{Sa}_{\mathrm{a}} \mathrm{O}_{2}\right)$ was monitored continuously by means of a portable pulsed oxymeter with an extensive and solid memory (Pulsox 5; Minolta, Japan). Cardiac frequency and respiratory frequency $(f R)$ were monitored by means of a pneumograph (Kolormon module 7271; Kontron Instruments, Watford, UK) with three surface electrodes placed on the chest and on the upper abdomen.

Baseline breathing pattern was assessed by means of a portable spirometer (Pony class 1 Type B; Cosmed, Roma, Italy) in nontracheostomized patients. In eight of these patients, respiratory inductance plethysmography (RIP) (Respitrace plus; Ambulatory Monitoring, Ardsley, NY, USA) was also used to assess the time course of $f \mathrm{R}$ and tidal volume $(V \mathrm{~T})$. Quantitative diagnostic calibration [15] was performed to calibrate the sum of rib cage and abdominal signals against the $V \mathrm{~T}$ signal of the spirometer with the patients in the sitting position. The separate values of rib cage and abdominal signals were not recorded.

In the five tracheostomized patients, flow $\left(V^{\prime}\right)$ and proximal airway pressure $(P$ aw $)$ were measured with a pneumotachograph/pressure transducer (Bicore, Irvine, CA, USA) inserted at the end of the tracheostomy cannula. Volume $(V)$ was determined by integration of the flow signal. Changes in pleural pressure were estimated from changes in oesophageal pressure $\left(P_{\text {oes }}\right)$. Poes was measured with an oesophageal balloon catheter connected to a differential pressure tranducer $\left( \pm 140 \mathrm{cmH}_{2} \mathrm{O}\right.$; Bicore, Irvine, CA, USA). $V \mathrm{~T}$, inspiratory and expiratory time ( $t \mathrm{I}$ and $t \mathrm{E}$, respectively), total cycle duration ( $t$ tot), $f \mathrm{R}$, mean inspiratory flow $(V \mathrm{~T} / t \mathrm{I})$ and the duty cycle $(t \mathrm{I} / t \mathrm{tot})$, and minute ventilation $\left(V^{\prime} \mathrm{E}\right)(V \mathrm{~T} \times f \mathrm{R})$ were obtained as average values from 120 $\mathrm{s}$ of continuous records of flow and volume. Poes swings were analysed measuring peak amplitude from the immediately preceding end-expiratory value. Patient WOB was assessed by calculating the area under the Poes versus lung volume curve during the negative deflection of $P$ oes tracings. Maximal static inspiratory $P_{\text {oes }}\left(P_{\text {oes,max }}\right)$ was assessed by means of a Muller manoeuvre during a maximal inspiratory effort generated after manual occlusion of the flow transducer starting from FRC. The subjects were verbally encouraged to achieve maximal strength. The highest value (most negative $P_{\mathrm{oes}}$ ) of three tests was considered in data analysis. Pressure time index (PTI) was calculated as $P_{\text {oes }} / P_{\text {oes, }}$ max $\times t \mathrm{I} / t$ tot. Dynamic intrinsic positive endexpiratory pressure $(\mathrm{PEEPi})$ was measured as the negative deflection in Poes from the onset of inspiratory effort to the onset of inspiratory flow [16]. We measured $P_{\text {oes }}$ swings as well as the pressure-time product for the inspiratory muscles (PTP). Tidal PTP values were obtained by measuring the area (integral of $P_{\text {oes }} \times \mathrm{dt}$ ) under the $P_{\text {oes }}$ versus time relationship. This was calculated as the value for a period of $120 \mathrm{~s}$. PTP per minute (PTPmin) was calculated as tidal PTP multiplied by $f \mathrm{R}$.

All patients adopted a semirecumbent position. After the application of topical anaesthesia (xylocaine spray 10\%), the balloon-tipped catheter was inserted through the nose into the oesophagus. The oesophageal balloon was inflated automatically and an occlusion test [17] was performed to verify correct positioning. The oesophageal balloon and the flow sensor were connected, through a portable monitor 
(CP-100, Bicore) providing real time display of flow, volume and $P_{\text {oes }}$ tracings, to a personal computer (Pentium; Compaq, Houston, TX, USA). Subsequent data analysis was performed using the software package Anadat (RHTinfoDat, Montreal, Quebec, Canada). After 15 min of breathing with the oesophageal catheter and having become confident with the settings, $P$ aw, $V^{\prime}$ and $P$ oes were transmitted to the monitor and recorded for $120 \mathrm{~s}$. The final mechanics data were collected as average data of at least four breathing acts, eliminating those affected by artifactual $P_{\text {oes }}$ variations. Reliability and accuracy of the Bicore CP-100 pulmonary device in spontaneously breathing patients has been demonstrated previously [18].

Subjective rating of dyspnoea was performed in all patients by means of a visual analogue scale (VAS).

\section{Treatment procedures}

Studies were performed at an inspiratory oxygen fraction $\left(F \mathrm{I}, \mathrm{O}_{2}\right)$ of 0.21 in all patients except two, in whom the study was performed at an $F \mathrm{I}_{2} \mathrm{O}_{2}$ of 0.24 . Before starting the study, all subjects completed six sessions of $30 \mathrm{~min}$ of DB training in the 3 days before the study, assisted by the same certified respiratory therapist. In the semirecumbent position the patients were instructed to inspire maximally, predominantly with abdominal motion, while reducing upper rib cage motion. Tactile feedback was given with one hand of the patient on the abdomen and the other hand on the upper rib cage [8]. Strict visual observation ensured that the respiratory therapist was confident that the patients used a DB pattern.

An A-B-A design was followed for the study. In phase A, with the patients in a semirecumbent position and the measurement devices on, measurements and monitoring were recorded during the final 5 of $15 \mathrm{~min}$ of natural breathing, defined as the naturally adopted pattern of breathing. In phase $\mathrm{B}$ measurements and monitoring were recorded during $15 \mathrm{~min}$ of DB. The first phase A started after stabilization of transcutaneous monitoring; phase $\mathrm{B}$ and second phase A followed immediately.

\section{Statistical design}

All data are expressed as mean \pm sD. Unpaired t-test was used to assess differences between tracheostomized and nontracheostomized patients. Analysis of variance (ANOVA) for repeated measures was used to test differences between phases. A post hoc test was added when indicated by ANOVA interaction. All the results of multiple comparison were corrected using the Bonferroni test. A pvalue of less than 0.05 was considered significant. Linear regression analysis was used to compare RIP and pneumograph for $f \mathrm{R}$ assessment and to compare arterial and transcutan-eous gases.

\section{Results}

Demographic, anthropometric and functional characteristics of all patients in the study are illustrated in table 1, in which the characteristics of the five tracheostomized patients are also shown. Patients suffered from chron-
Table 1. - Anthropometric and functional characteristics of patients

\begin{tabular}{|c|c|c|}
\hline & Nontracheostomized & Tracheostomized \\
\hline Subjects $n$ & 20 & 5 \\
\hline Age yrs & $64 \pm 8$ & $68 \pm 3$ \\
\hline Sex M/F & $18 / 2$ & $5 / 0$ \\
\hline Weight $\mathrm{kg}$ & $66 \pm 17$ & $56 \pm 14$ \\
\hline Height $\mathrm{cm}$ & $170 \pm 4$ & $173 \pm 5$ \\
\hline$f \mathrm{C}$ beats $\cdot \min ^{-1}$ & $90 \pm 15$ & $94 \pm 20$ \\
\hline $\mathrm{pH}$ & $7.37 \pm 0.02$ & $7.37 \pm 0.03$ \\
\hline $\mathrm{P}_{\mathrm{a}, \mathrm{CO}_{2}} \mathrm{mmHg} / \mathrm{kPa}$ & $51 \pm 5 / 6.7 \pm 0.6$ & $52 \pm 7 / 6.84 \pm 0.92$ \\
\hline $\mathrm{Pa}_{\mathrm{a}} \mathrm{O}_{2} \mathrm{mmHg} / \mathrm{kPa}$ & $51 \pm 5 / 6.7 \pm 0.6$ & $51 \pm 3 / 6.71 \pm 0.39$ \\
\hline $\mathrm{S}_{\mathrm{a}, \mathrm{O}_{2}} \%$ & $88 \pm 2$ & $88 \pm 3$ \\
\hline$V \mathrm{~T} \mathrm{~mL}$ & $429 \pm 144$ & $362 \pm 130$ \\
\hline$f_{\mathrm{R}}$ breaths $\cdot \mathrm{min}^{-1}$ & $18 \pm 1$ & $21 \pm 4 * * *$ \\
\hline$V^{\prime} \mathrm{E} \mathrm{L} \cdot \mathrm{min}^{-1}$ & $7.6 \pm 0.8$ & $7.5 \pm 1$ \\
\hline FVC $\%$ pred & $51 \pm 22$ & $41 \pm 8$ \\
\hline FEV1 $\%$ pred & $38 \pm 21$ & $34 \pm 8$ \\
\hline FEV1/FVC \% & $46 \pm 12$ & $47 \pm 16$ \\
\hline TLC \% pred & $143 \pm 16$ & $137 \pm 9$ \\
\hline RV \% pred & $159 \pm 46$ & $168 \pm 24$ \\
\hline MIP $\%$ pred & $44 \pm 11$ & $35 \pm 5$ \\
\hline
\end{tabular}

Values are presented as absolute number and mean \pm sD. $* * *$ : $\mathrm{p}<0.001$ versus nontracheostomized patients; there were no other significant differences. M: male; F: female; $f \mathrm{c}$ : cardiac frequency; $P \mathrm{a}, \mathrm{CO}_{2}$ : arterial carbon dioxide tension; $P \mathrm{a}, \mathrm{O}_{2}$ : arterial oxygen tension; $\mathrm{Sa}_{\mathrm{a}} \mathrm{O}_{2}$ : arterial oxygen saturation; $V \mathrm{~T}$ : tidal volume; $f \mathrm{R}$ : respiratory frequency; $V^{\prime} \mathrm{E}$ : minute ventilation; FVC: forced vital capacity; \% pred: percentage of predicted value; FEV1: forced expiratory volume in one second; TLC: total lung capacity; RV: residual volume; MIP: maximal inspiratory pressure.

ic hypercapnia, showed a severe level of airway obstruction with hyperinflation and their inspiratory muscle strength was reduced (fig. 1). No significant correlation was found between MIP and FVC ( $\mathrm{r}=0.23, \mathrm{p}=0.26)$. No significant differences were observed between the two groups of patients, in terms of anthropometrics, lung function, arterial blood gases and inspiratory muscle function. Tracheostomized patients showed a significantly higher $f \mathrm{R}$ and a nonsignificantly lower $V \mathrm{~T}$, resulting in similar $V^{\prime} \mathrm{E}$. Time course of mean $P \mathrm{tc}, \mathrm{CO}_{2}, P \mathrm{tc}, \mathrm{O}_{2}$ and $\mathrm{Sa}_{\mathrm{a}} \mathrm{O}_{2}$ in the different phases (A-B-A) for all patients are shown in table 2. In comparison to natural breathing deep DB was associated throughout the $\mathrm{B}$ phase, with a stable significant increase

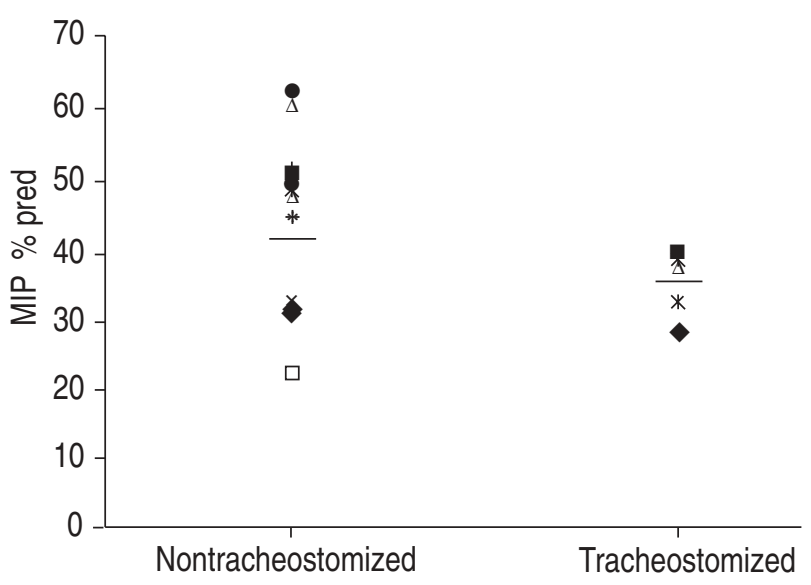

Fig. 1. - Individual values of maximal inspiratory pressure (MIP) in patients in the study. Horizontal bars represent the means. 
Table 2. - Transcutaneous gases, cardiac frequency $(f C)$ and breathing pattern during diaphragmatic breathing

\begin{tabular}{|c|c|c|c|c|c|}
\hline & \multirow{2}{*}{$\begin{array}{c}\text { Phase A } \\
\text { (baseline) }\end{array}$} & \multicolumn{3}{|c|}{ Phase B } & \multirow[t]{2}{*}{ Phase A } \\
\hline & & 5th min & 10th min & 15th min & \\
\hline$P_{\mathrm{tc}, \mathrm{O}_{2}} \quad \mathrm{kPa}$ & $7.1 \pm 0.6$ & $7.9 \pm 0.1$ & $8.0 \pm 0.5$ & $8.0 \pm 0.6 * *$ & $7.0 \pm 0.8$ \\
\hline$P_{\mathrm{tc}, \mathrm{CO}_{2}} \quad \mathrm{kPa}$ & $7.2 \pm 1.2$ & $7.0 \pm 0.6$ & $6.8 \pm 0.6$ & $6.8 \pm 0.5^{*}$ & $7.0 \pm 0.5$ \\
\hline $\mathrm{Sa}_{\mathrm{a}, \mathrm{O}_{2}} \quad \%$ & $90 \pm 2$ & $93 \pm 3$ & $94 \pm 3$ & $93 \pm 5$ & $91 \pm 2$ \\
\hline$f \mathrm{c}$ beats $\cdot \mathrm{min}^{-1}$ & $90 \pm 17$ & $88 \pm 10$ & $89 \pm 5$ & $90 \pm 2$ & $87 \pm 5$ \\
\hline$f \mathrm{R}$ breaths $\mathrm{min}^{-1}$ & $19 \pm 5$ & $14 \pm 3$ & $15 \pm 4$ & $14 \pm 3$ & $20 \pm 4$ \\
\hline$V \mathrm{~T} \mathrm{~mL}^{+}$ & $543 \pm 130$ & $1140 \pm 570$ & $1200 \pm 590$ & $1250 \pm 460^{\#}$ & $573 \pm 168$ \\
\hline$f \mathrm{R}$ breaths $\cdot \min ^{-1+}$ & $18 \pm 3$ & $12 \pm 3$ & $12 \pm 4$ & $11 \pm 5 \S$ & $16 \pm 4$ \\
\hline$V^{\prime} \mathrm{E} L \cdot \mathrm{min}^{-1+}$ & $10 \pm 3$ & $14 \pm 5$ & $15 \pm 4$ & $14 \pm 4 \S$ & $9 \pm 6$ \\
\hline
\end{tabular}

Values are presented as mean \pm SD. $P \mathrm{tc}, \mathrm{O}_{2}:$ transcutaneous partial pressure of oxygen; $P_{\mathrm{tc}, \mathrm{CO}_{2}: \text { transcutaneous partial pressure }}$ of carbon dioxide. $f \mathrm{R}$ : respiratory frequency measured by means of a pneumograph. *: $\mathrm{p}<0.05 ; * *: \mathrm{p}<0.01 ; \xi: \mathrm{p}<0.005 ; \#$ : $\mathrm{p}<0.0001$, versus phase A (baseline). +: data available in eight patients. In these eight patients $f \mathrm{R}$ was obtained from respiratory inductance plethysmography. For further definitions, see legend to table $1.1 \mathrm{kPa}=7.5 \mathrm{mmHg}$
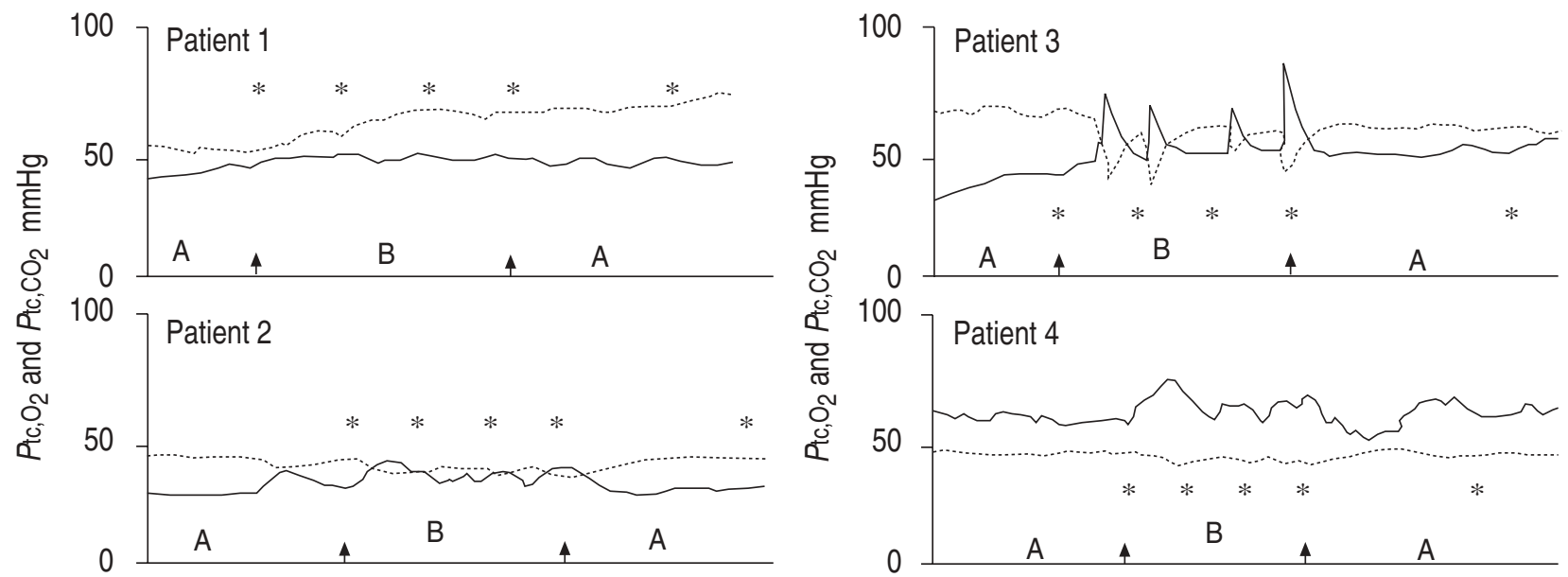

Fig. 2. - Representative tracings of transcutaneous carbon dioxide tension $\left(P_{\mathrm{tc}, \mathrm{CO}_{2} ; \cdots \cdots} ; \cdots\right)$ and transcutaneous oxygen tension $\left(P_{\mathrm{tc}, \mathrm{O}_{2}} ;-\frac{1}{-}\right)$ in four patients during natural (A) and diaphragmatic breathing (B). Arrows represent the beginning and end of phase B (15 min). Asteristics represent the times at which values of transcutaneous gases were considered for statistical analysis. During phase $\mathrm{B}$ in $\mathrm{Patient}_{\mathrm{e}} 1, P_{\mathrm{tc}, \mathrm{CO}_{2}}$ increased, Patient 2 showed unchanged values of both $P \mathrm{tc}, \mathrm{CO}_{2}$ and $P \mathrm{tc}, \mathrm{O}_{2}$, while Patients 3 and 4 had improvement in both $P \mathrm{tc}, \mathrm{CO}_{2}$ and $P \mathrm{tc}, \mathrm{O}_{2}$ with wide oscillations due to inability to maintain diaphragmatic breathing for prolonged periods. $1 \mathrm{mmHg}=0.133 \mathrm{kPa}$.
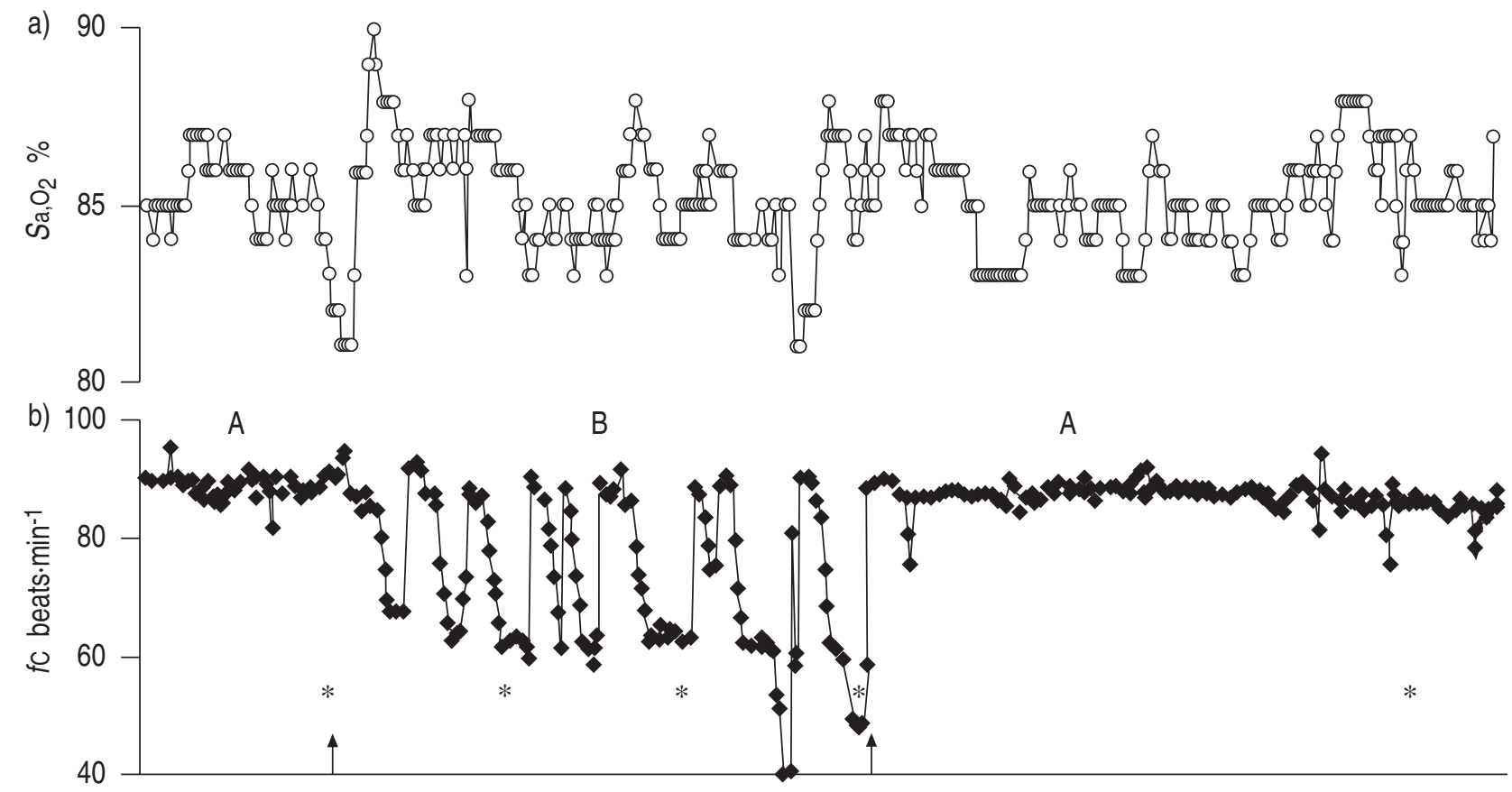

Fig. 3. - Representative tracing of a) arterial oxygen tension $\left(\mathrm{S}_{\mathrm{a}}, \mathrm{O}_{2}\right)$ and b) cardiac frequency $(f \mathrm{C})$ in a patient during natural $(\mathrm{A})$ and diaphragmatic breathing (B). Arrows represent beginning and end of phase B (15 min). Asteristics represent values considered for statistical analysis. 
Table 3. - Transcutaneous gases, breathing pattern and mechanics during diaphragmatic breathing in tracheostomized patients $(n=5)$

\begin{tabular}{|c|c|c|c|}
\hline & Phase A (baseline) & Phase B & Phase A \\
\hline$\overline{V T} \mathrm{~mL}$ & $362 \pm 130$ & $952 \pm 370^{\#}$ & $400 \pm 150$ \\
\hline$f_{\mathrm{R}}$ breaths $\cdot \min ^{-1}$ & $21 \pm 4$ & $10 \pm 6^{\#}$ & $15 \pm 4 \S$ \\
\hline$t \mathrm{I} \mathrm{S}$ & $1.25 \pm 0.13$ & $2 \pm 0.1 \S$ & $1.33 \pm 0.14$ \\
\hline$t \mathrm{E} \mathrm{S}$ & $1.64 \pm 0.1$ & $3.98 \pm 0.2^{\#}$ & $1.90 \pm 0.14$ \\
\hline$t \mathrm{t} / t$ tot & $0.41 \pm 0.02$ & $0.35 \pm 0.08 *$ & $0.40 \pm 0.04$ \\
\hline$V \mathrm{~T} / t \mathrm{I} \mathrm{L} \cdot \mathrm{s}^{-1}$ & $0.27 \pm 0.06$ & $0.31 \pm 0.08 *$ & $0.28 \pm 0.06$ \\
\hline$V^{\prime} \mathrm{E} L \cdot \mathrm{min}^{-1}$ & $7.5 \pm 1$ & $10 \pm 2$ & $6.1 \pm 2 * *$ \\
\hline$f \mathrm{R} / V \mathrm{~T}$ & $87 \pm 20$ & $13 \pm 9 \#$ & $40 \pm 10^{\S}$ \\
\hline$P_{\text {oes swing }} \mathrm{cmH}_{2} \mathrm{O}$ & $13 \pm 2$ & $23 \pm 5 \S$ & $15 \pm 3$ \\
\hline $\mathrm{PEEPi} \mathrm{cmH}_{2} \mathrm{O}$ & $2.67 \pm 1$ & $10 \pm 38$ & $4 \pm 2 * *$ \\
\hline PTPmin $\quad \mathrm{cmH}_{2} \mathrm{O} \cdot \mathrm{s} \cdot \mathrm{min}^{-1}$ & $262 \pm 67$ & $390 \pm 120 * *$ & $280 \pm 70$ \\
\hline WOB $\mathrm{J} \cdot \mathrm{L}^{-1}$ & $1.31 \pm 0.20$ & $2.26 \pm 1^{\S}$ & $1.50 \pm 0.80$ \\
\hline$P_{\text {oes, } \max } \mathrm{cmH}_{2} \mathrm{O}$ & $37 \pm 4$ & & \\
\hline PTI & $0.15 \pm 0.02$ & $0.23 \pm 0.06 \S$ & $0.16 \pm 0.03$ \\
\hline$P \mathrm{tc}, \mathrm{O}_{2} \mathrm{kPa}$ & $6.97 \pm 0.39$ & $7.89 \pm 0.26 * *$ & $7.10 \pm 0.52$ \\
\hline$P \mathrm{tc}, \mathrm{CO}_{2} \mathrm{kPa}$ & $7.89 \pm 0.52$ & $7.63 \pm 0.65$ & $7.76 \pm 0.78$ \\
\hline
\end{tabular}

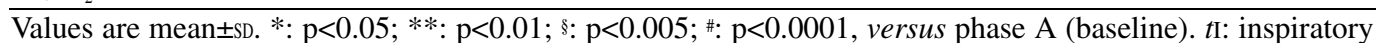
time; $t \mathrm{E}$; expiratory time; $t$ tot: total breathing duration; $P$ oes: oesophageal pressure; PEEPi: intrinsic positive end-expiratory pressure; PTPmin: pressure-time product per minute; WOB: work of breathing; $P$ oes, max: maximal static inspiratory $P$ oes; PTI: pressure-time index; $P \mathrm{tc}, \mathrm{O}_{2}$ : transcutaneous oxygen tension; $P_{\mathrm{tc},} \mathrm{CO}_{2}$ : transcutaneous carbon dioxide tension. For further definitions see legend to table $1.1 \mathrm{kPa}=7.5 \mathrm{mmHg}$.
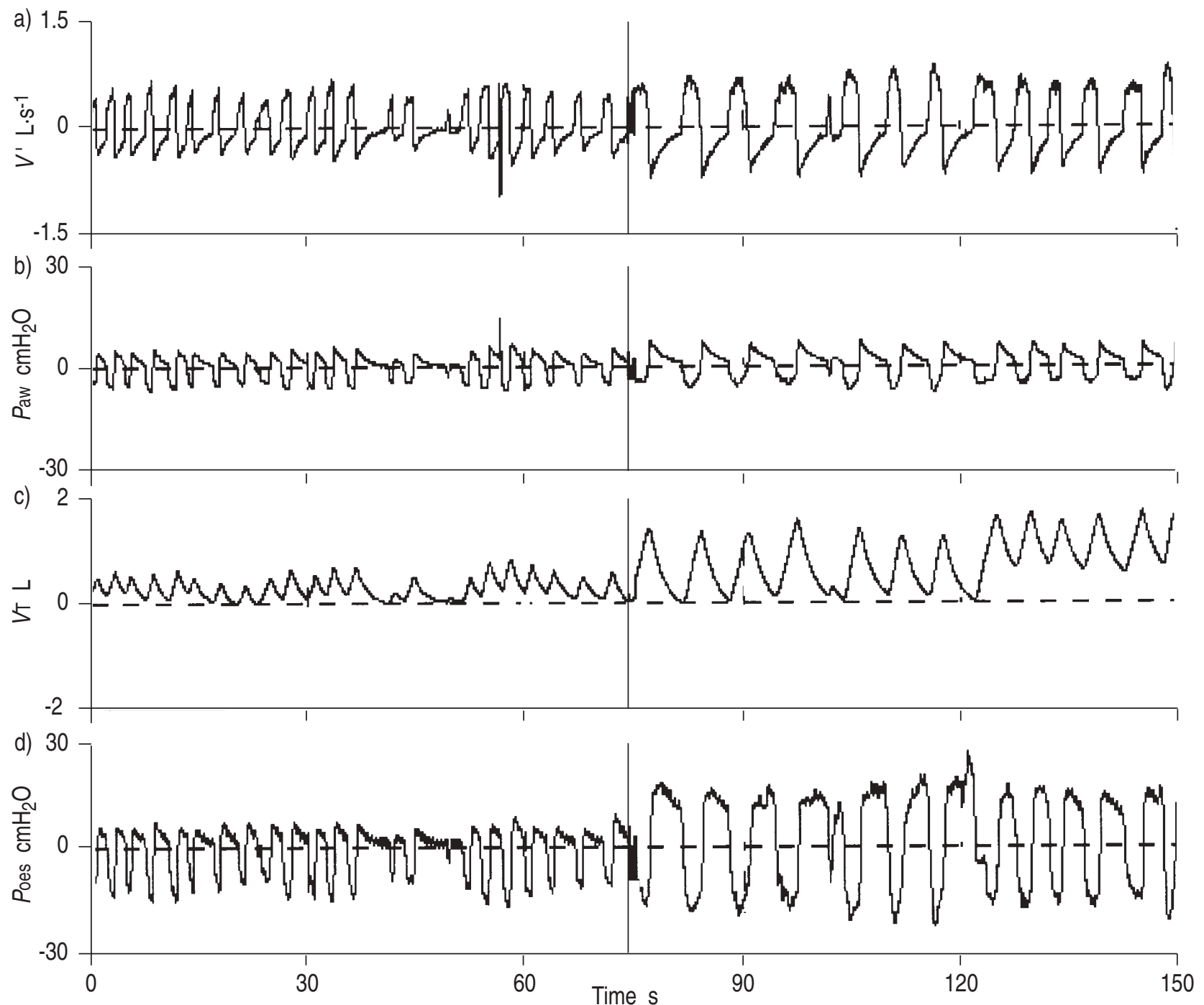

Fig. 4. - Representative tracing of a) flow $\left(V^{\prime}\right)$, b) airway pressure $\left(P_{\text {aw }}\right)$, c) tidal volume $(V \mathrm{~T})$ and d) oesophageal pressure $\left(P_{\mathrm{oes}}\right)$ in a tracheostomized patient during natural and diaphragmatic breathing. The vertical line through the figures shows the transition from natural (left) to diaphragmatic breathing (right). During diaphragmatic breathing respiratory frequency decreased and $V \mathrm{~T}$ and $P_{\mathrm{oes}}$ swing increased. 
in $P \mathrm{tc}, \mathrm{O}_{2}$ and a significant decrease in $P \mathrm{tc}, \mathrm{CO}_{2} . \mathrm{Sa}_{\mathrm{a}} \mathrm{O}_{2}$ also increased, although not significantly. All patients had improved oxygenation, whereas in six out of 25 patients $P \mathrm{tc}, \mathrm{CO}_{2}$ did not change. Patients in whom $P \mathrm{tc}, \mathrm{CO}_{2}$ did improve differed from the others in terms of baseline $V \mathrm{~T}(452 \pm 121$ versus $300 \pm 102 \mathrm{~mL}, \mathrm{p}<0.01) ; \mathrm{fR}(17 \pm 2$ versus $20 \pm 2$ breaths $\left.\cdot \min ^{-1}, \mathrm{p}<0.01\right)$ and $f \mathrm{R} / V \mathrm{~T}$ ratio, whereas no significant difference was found in anthropometric data, baseline arterial blood gases and spirometric values, or in inspiratory muscle function. Representative tracings of transcutaneous and pulse oxymetry recordings are shown in figures 2 and 3 , respectively. The time course of $V \mathrm{~T}$ and $f \mathrm{R}$ is also shown in table 2. Assessment of breathing pattern with RIP in eight patients showed that deep DB was associated with a significant increase in $V \mathrm{~T}$ and a significant reduction in $f \mathrm{R}$ resulting in significantly increased $V^{\prime} \mathrm{E}$. Comparison of values of $f \mathrm{R}$ evaluated by RIP and the pneumograph respectively showed a strong linear correlation $(\mathrm{r}=0.75)$. During DB, VAS showed a significant worsening (from 33 \pm 9 to $54 \pm 9 \%, \mathrm{p}<0.01)$.

Changes in physiological parameters assessed in the five tracheostomized patients are shown in table 3 . The natural breathing pattern of these patients was characterized by a low $V \mathrm{~T}$ and a high $f \mathrm{R}$ PEEPi was measurable. DB was associated with increased $V \mathrm{~T}$ and reduced $f \mathrm{R}$ resulting in significantly increased $V^{\prime} \mathrm{E}$, thus confirming the data observed in the eight patients studied with RIP. The $t \mathrm{t} / t$ tot ratio decreased significantly, whereas mean inspiratory flow $(V \mathrm{~T} / t \mathrm{I})$ increased. Inspiratory muscle effort increased, as demonstrated by an increase in $P_{\text {oes }}$ swing (fig. 4), PTPmin and WOB. PTI, an index of muscle fatigue, also increased. DB was associated with an increase in PEEPi. Transcutaneous evaluation of blood gases showed a behaviour similar to the whole population of patients (table 3).

\section{Discussion}

The present study shows that in severe COPD patients with chronic hypercapnia and reduced inspiratory muscle strength recovering from an episode of acute respiratory failure, deep diaphragmatic breathing is able to improve blood gases and increase $V^{\prime} \mathrm{E}$, whereas inspiratory muscle effort increases and dyspnoea worsens. This study confirms and extends, in more severe patients the detrimental effects of DB found by Gosselink et al. [8] in COPD patients without chronic respiratory insufficiency. Furthermore, the present study also examined the effects of DB on respiratory mechanics in these severe patients.

Although respiratory rehabilitation has been shown to be beneficial in improving health-related quality of life and exercise capacity [1], the contribution of the components of the rehabilitation programmes has been less well defined [2]. Clearly, a better understanding of the components will have important implications for resource allocation as respiratory rehabilitation becomes more widespread. Unfortunately, review of literature leads to the conclusion that the varied outcome measures used in several studies do not allow the real treatment effect of most interventions to be estimated. Furthermore, although DB is conventionally considered a component of respiratory rehabilitation [2, 3], its physiological effects have been even less studied. An early trial by Lustig et al. [19] suggested that breathing exercises alone may modify patients' anxiety and attitude toward work. TANDON [20] observed that training in yoga was more effective than chest physiotherapy in improving exercise tolerance in patients with severe COPD. In a randomized, controlled study, AmBRosino et al. [4] reported improvement in maximal exercise tolerance in mild COPD patients undergoing only deep DB and pursed-lip breathing. Nevertheless, few studies des-cribe the exact manoeuvres performed, and a recent meta-analysis concluded that in the absence of more detailed clinical trials, it is not possible to assess the value of these exercises [2].

In our study, DB resulted in significantly improved arterial blood gases as assessed by transcutaneous monitoring. $P$ tc, $\mathrm{O}_{2}$ and $P$ tc, $\mathrm{CO}_{2}$ are known to reflect changes in $P \mathrm{a}, \mathrm{O}_{2}$ and $P \mathrm{a}, \mathrm{CO}_{2}$ when factors such as cardiac output and the body position are unaltered [21-23]. Although the utility of individual measurements of $P \mathrm{tc}, \mathrm{CO}_{2}$ and $P \mathrm{tc}, \mathrm{O}_{2}$ as absolute reflections of arterial blood gases may be questioned, trancutaneous monitoring may well provide an estimate of the net changes resulting from the manoeuvres. $P$ tc, $\mathrm{O}_{2}$ im-proved, and because it was in the steep portion of the oxyhaemoglobin dissociation curve, $\mathrm{Sa}_{\mathrm{a}} \mathrm{O}_{2}$ also improved. The average and individual decreases in $P$ tc, $\mathrm{CO}_{2}$, although significant, were small; $24 \%$ of patients did not show such a decrease. Only a lower baseline $V \mathrm{~T}$ and a higher $f \mathrm{R}$ distinguished the patients in whom $P \mathrm{tc}, \mathrm{CO}_{2}$ did not change.

A possible explanation for the changes in blood gases may be found in an increase in alveolar ventilation, as suggested by the changes in breathing pattern during DB (fig. 3 ). Indeed DB was associated with a significant increase in $V \mathrm{~T}$ and a significant reduction in $f \mathrm{R}$ resulting in increased $V^{\prime}$ E. Although patients in the study of Gosselnk et al. [8] showed a trend to an increase in $V \mathrm{~T}$ during unloaded DB, in contrast to the present study, that increase was not significant. There are several factors that may explain this difference. The study design was different. The patients in the study of Gosselink et al. [8] were defined by an FEV1 similar to the present patients, but they were not chronically hypercapnic, as the present patients were. The present patients also showed a more compromised in-spiratory muscle strength as assessed by an MIP of $45 \pm 12$ $\mathrm{cmH}_{2} \mathrm{O}$ in comparison to $81 \pm 10 \mathrm{cmH}_{2} \mathrm{O}$ in the study of Gosselink et al. [8], respectively. Furthermore, the natural breathing pattern of the present patients was characterized by a greater mean $f \mathrm{R} / V \mathrm{~T}$ than in the study by Gosselink et al. [8]. Therefore, the baseline breathing pattern of the present patients, characterized by a higher $f \mathrm{R}$ and a lower $V \mathrm{~T}$, may have been more influenced by the DB manoeuvres. Moreover, in the present study the instructions for DB included maximal inspiration and this, rather than (or in addition to) changes in rib cage and abdominal relative contribution, may explain the results. Although we did not record the relative contribution of rib cage and abdominal compartments, strict visual observation made us confident that the patients used a DB pattern (see protocol).

Diaphragmatic breathing was associated with increased $V \mathrm{~T}$ and reduced $f \mathrm{R}$ and $t \mathrm{t} / t$ tot ratio decreased. The smaller $t \mathrm{t} / t$ tot ratio with a reduced $f \mathrm{R}$ may allow a slightly longer expiratory time which, at least theoretically, should in turn favour lung emptying [24] and respiratory muscle rest [25]. However, our data in the five tracheostomized patients in whom we measured mechanics did not confirm this assumption. Indeed, inspiratory muscle effort increased, as 
demonstrated by the increase in Poes swing (fig. 3), PTP and WOB. These results confirm the "detrimental" effect of this technique reported by Gosselink et al. [8]. In fact, these authors found that during unloaded DB, oxygen consumption did increase significantly, and this finding was attributed to a more abnormal chest wall motion during DB in comparison to natural breathing. PTP is considered to be an index of respiratory metabolic work indicating the patient's effort to breathe [26]. PTI, also referred to as the tension time index (TTI) can be found to be increased by any combination of increased resistance, decreased compliance, inspiratory muscle weakness and undernutrition, and during DB in our patients, increased to a mean value of 0.23 . The TTI for the human rib cage muscles $\left(P_{\text {oes }} \times P_{\text {oes, } m a x} \times t \mathrm{I} / t\right.$ tot $)$ indicating a critical level for fatigue in normal subjects was reported to range 0.300.55 [27]. The results of the present study are consistent with the finding that in stable COPD, PEEPi does not exceed a few centimetres of water (table 3) [28]. Although our patients were instructed to exhale without abdominal muscle contraction, the increase in PEEPi observed during DB may well be explained by a contraction of expiratory muscles [16]. Nevertheless, as we measured neither the gastric pressure [29] nor the electromyographic activity of the abdominal muscles, this remains speculative.

Although the lung function data were not significantly different between tracheostomized and other patients (table 1), the tracheostomized ones may be considered, at least theoretically, a more severe subgroup of patients. These patients showed a mean FVC $20 \%$ lower, and a $20 \%$ difference in MIP, which, although not statistically significant, might be clinically important (fig. 1). Indeed, the level of severity of these patients is also shown by the high $f \mathrm{R} / V \mathrm{~T}$

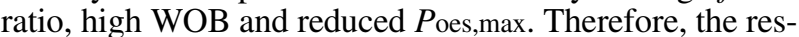
ults of mechanical studies in these patients must be extrapolated to all other patients with caution. Nevertheless, our mechanical studies may give useful information on the effects of DB not reported before.

In agreement with Gosselink et al. [8], in the present patients dyspnoea sensation tended to increase during DB compared with natural breathing. Similar results were reported in normal subjects during loaded DB by STUBBINg $e t$ al. [30].

The present study is a short-term one and its conclusions must be confirmed by long-term studies. Whether the "detrimental" acute physiological effects can be offset in the long-term by more favourable effects, such as improvement in blood gases, remains to be established. As a matter of fact, the detrimental effects observed by GosselnK et al. [8] with DB were not permanently pres-ent during natural breathing, thus indicating that the DB pattern was not adopted as the natural pattern. Nevertheless, short-term studies are required before longer-term in-vestigation of therapeutic interventions, in order to show at least the tolerance of the patients to the treatment.

In conclusion, our study shows that in severe chronic obstructive pulmonary disease patients with chronic hypercapnia and reduced inspiratory muscle strength, recovering from an episode of acute respiratory failure, deep diaphragmatic breathing, a common component of respiratory rehabilitation programmes, may induce an acute improvement in arterial blood gases while increasing inspiratory muscle effort and worsening dyspnoea. An increase in alveolar ventilation as suggested by the modifications of breathing pat- tern was likely to be the major mechanism through which diaphragmatic breathing improved the arterial blood gases.

\section{References}

1. Lacasse Y, Wong E, Guyatt GH, Cook DJ, Goldstein RS. Meta-analysis of respiratory rehabilitation in chronic obstructive pulmonary disease. Lancet 1996; 348: 1115-1119.

2. Lacasse Y, Guyatt GH, Goldstein RS. The components of a respiratory rehabilitation program. A systematic overview. Chest 1997; 111: 1077-1088.

3. Faling LJ. Controlled breathing techniques and chest physical therapy in chronic obstructive pulmonary disease and allied conditions. In: Casaburi R, Petty TL, eds. The Principles and Practice of Pulmonary Rehabilitation. Philadelphia, Saunders WB, 1993; pp. 167-182.

4. Ambrosino N, Paggiaro PL Macchi M, et al. A study of short-term effect of rehabilitative therapy in chronic obstructive pulmonary disease. Respiration 1981; 41: $40-44$.

5. Sackner MA, Gonzales HF, Jenouri G, Rodriguez M. Effects of abdominal and thoracic breathing on breathing pattern components in normal subjects and in patients with COPD. Am Rev Respir Dis 1984; 130: 584-587.

6. Grimby G, Oxhoj H, Bake B. Effects of abdominal breathing on distribution of ventilation in obstructive lung disease. J Rehab Sci 1993; 6: 66-87.

7. Williams IP, Smith CM, McGavin CR. Diaphragmatic breathing training and walking performance in chronic airways obstruction. Br J Dis Chest 1982; 76: 164-166.

8. Gosselink RAM, Wagenaar RC, Rijswijk H, Sargeant AJ, Decramer MLA. Diaphragmatic breathing reduces efficiency of breathing in patients with chronic obstructive pulmonary disease. Am J Respir Crit Care Med 1995; 151: $1136-1142$.

9. ATS statement. Standards for the diagnosis and care of patients with chronic obstructive pulmonary disease. Am J Respir Crit Care Med 1995; 152: S77-S120.

10. Siafakas NM, Vermeire P, Pride NB, et al. ERS Consensus Statement. Optimal assessment and management of chronic obstructive pulmonary disease (COPD). Eur Respir $J$ 1995; 8: 1398-1420.

11. Quanjer PH. Working Party on "Standardization of lung function test". Bull Eur Physiopathol Respir 1983; 19 (Suppl. 5): 7-10.

12. Black L, Hyatt R. Maximal airway pressures: normal values and relationship to age and sex. Am Rev Respir Dis 1969; 99: 696-702.

13. Bruschi C, Cerveri I, Zoia MC, et al. Reference values of maximal respiratory mouth pressures: A population-based study. Am Rev Respir Dis 1992; 146: 790-793.

14. Herala M, Gislason T. Chest physiotherapy. Evaluation by transcutaneous blood gas monitoring. Chest 1988; 93: 4: 800-802.

15. Sackner MA, Watson H, Belsito AS, et al. Calibration of respiratory inductive plethysmograph during natural breathing. J Appl Physiol 1989; 66: 410-420.

16. Ninane V, Yernault JC, De Troyer A. Intrinsic PEEP in patients with chronic obstructive pulmonary disease: role of expiratory muscles. Am Rev Respir Dis 1993; 148: 1037-1042.

17. Baydur A, Behrakis K, Zin WA, Jaeger M, Milic-Emili J. A simple method for assessing the validity of the esophageal balloon technique. Am Rev Respir Dis 1982; 126: 
788-791.

18. Vitacca M, Clini E, Porta R, Foglio K, Ambrosino N. Acute exacerbations in patients with COPD requiring hospital admission: correlates of short-term outcome. Eur Respir J 1996; 9: 1487-1493.

19. Lustig FM, Haas A, Castillo R. Clinical and rehabilitation regime in patients with chronic obstructive pulmonary disease. Arch Phys Med Rehab 1972; 52: 315-322.

20. Tandon MK. Adjunct treatment with yoga in chronic severe airways obstruction. Thorax 1978; 33: 514-517.

21. Blanchette T, Dziodzio J. Transcutaneous $\mathrm{PCO}_{2}$ and end-tidal $\mathrm{PCO}_{2}$ in ventilated adults. Respir Care 1991; 37: 240-248.

22. Clark J, Votteri B, Ariagno R, et al. Non-invasive assessesment of blood gases. Am Rev Respir Dis 1992; 145: 220-232.

23. Sanders MH, Kern NB, Costantino C, et al. Accuracy of end-tidal and trancutaneous $\mathrm{PCO}_{2}$ monitoring during sleep. Chest 1994; 106: 472-483.

24. Rossi A, Polese G, Brandi G. Dynamic hyperinflation. In: Marini JJ, Roussos C, eds. Ventilatory Failure. Berlin, Springer Verlag, 1991; 15: pp. 199-218.

25. Roussos C, Macklem PT. Inspiratory muscle fatigue. In: Macklem PT, Mead J, eds. Handbook of physiology. Sec- tion 3. The Respiratory System. Bethesda, American Physiological Society 1986; pp. 511-527.

26. Field S, Grassino A. Sanci S. Respiratory muscle oxygen consumption estimated by the diaphragm pressure-time index. J Appl Physiol 1984; 57: 44-51.

27. Zocchi L, Fitting JW, Majani U, Fracchia C, Rampulla C, Grassino A. Effect of pressure and timing of contraction on human rib cage muscles fatigue. Am Rev Respir Dis 1993; 147: 857-864.

28. Dal Vecchio L, Polese G, Poggi R, Rossi A. "Intrinsic" positive end-expiratory pressure in stable patients with chronic obstructive pulmonary disease. Eur Respir J 1990; 3: 74-80.

29. Appendini L, Patessio A, Zanaboni S, et al. Physiological effects of positive end-expiratory pressure and mask pressure support during exacerbations of chronic obstructive pulmonary disease. Am J Respir Crit Care Med 1994; 149: 1069-1076.

30. Stubbing DG, Ramsdale EH, Killian KJ, Campbell EJM. Psychophysics of inspiratory muscle force. J Appl Physiol 1983; 54: 1216-1221. 